\title{
Metabolic effects of coconut, safflower, or menhaden oil feeding in lean and obese Zucker rats
}

\author{
BY PAMARTHI F. MOHAN, FREDERICK C. PHILLIPS \\ AND MARGOT P. CLEARY \\ Hormel Institute, University of Minnesota, Austin, Minnesota 55912, USA
}

(Received 12 December 1989 - Accepted 10 December 1990)

\begin{abstract}
The aim of the present investigation was to study the effects of fish oil feeding in obese Zucker rats to establish its suitability as an animal model of hyperlipidaemia, and to understand the possible mechanism of fish oil-induced perturbations in cell metabolism. Lean and obese Zucker rats were fed on diets containing $180 \mathrm{~g}$ coconut, safflower, or menhaden oil $/ \mathrm{kg}$ for 10 weeks. Body-weights and food intakes of lean coconut (LC), safflower (LS), and menhaden (LM) groups were similar. Obese menhaden (OM) rats had lower food intakes and body-weights compared with obese coconut $(\mathrm{OC})$ and obese safflower (OS) groups, but values for all obese rats were higher than those for lean rats. Liver weights were higher in obese compared with lean rats, but on a percentage body-weight basis menhaden oil rats had higher values within genotype. Serum cholesterol and triacylglycerol levels were lower in the OM group compared with the OC and OS groups, and in the LM group compared with the LC group. Glucose and insulin levels were highest in $O S$ rats followed by $O C$ and $O M$ rats and then the lean rats. Serum triiodothyronine and thyroxine were lower in OM rats compared with $O C$ and $O S$ rats. Liver mitochondrial state 3 rates with glutamate-malate and succinate were lower; mitochondrial $\beta$-oxidation was unaffected and peroxisomal $\beta$-oxidation was higher in menhaden oil rats compared with both coconut and safflower oil rats. In general, consumption of menhaden oil lowered hepatic malic enzyme (EC 1.1.1.38, 1.1.1.40), glucose-6-phosphate dehydrogenase $(E C 1.1 .1 .49)$ and glutathione peroxidase $(E C$ 1.11.1.9) activities and elevated long-chain fatty acyl-CoA hydrolase $(E C 3.1 .2 .2)$ activity when compared with the two other diets. It is concluded that obese Zucker rats do respond like human subjects to fish oil feeding but not to vegetable oils. The hypolipidaemic effect of fish oil appears to be mediated through a lowering of lipogenic enzymes, glucose-6-phosphate dehydrogenase and malic enzyme.
\end{abstract}

Cholesterol: Triacylglycerol: Glucose: Insulin

There has been great interest in recent years in the use of fish oil as a therapeutic agent in the treatment of hyperlipidaemia. Feeding diets rich in fish oil has been shown to be beneficial against cardiovascular disease including atherosclerosis and thrombosis (Kinsella, 1987; Leaf \& Weber, 1988). These effects of fish oil have been related to their high concentrations of $n-3$ polyunsaturated fatty acids, particularly eicosapentaenoic acid, 20:5n-3 (EPA), and docosahexaenoic acid, 22:6n-3 (DHA). In general, serum triacylglycerol levels appear to be lowered to a greater degree and more consistently than do serum cholesterol levels (for review see Harris, 1989). This is true for both normolipaemic and hyperlipaemic individuals although hyperlipaemic subjects have been more likely also to have effects on serum cholesterol. To some extent, feeding of vegetable oils has also been shown to elicit similar responses but with a lower magnitude (Harris et al. 1983).

Hyperlipidaemia is frequently associated with a genetic component, thus animal models with genetic hyperlipidaemia might be useful in evaluating mechanisms of fish oil action. However, relatively few studies using such animals have been reported in the literature. Several recent studies have used fish oil-fed Watanabe rabbits. Both Clubb et al. (1989) and 
Rich et al. (1989) concluded from their studies that fish oil feeding did not reduce the severity of atherosclerosis in these rabbits. One study of fish oil feeding has been reported for LA/N hypertriacylglycerolaemic corpulent rats (Dolphin et al. 1988). Both male and female corpulent rats had lower cholesterol levels and triacylglycerol levels after 2 months of consuming a standard laboratory rat food enriched with red fish oil than did corpulent rats without the fish oil supplement, although triacylglycerol levels were still substantially above those of lean normolipidaemic rats.

The genetically obese Zucker rat is both hypertriacylglycerolaemic and hypercholesterolaemic (Zucker \& Zucker, 1962; Zucker, 1965) and, thus, may provide a better model for some types of human hyperlipidaemia. The aim of the present investigation was to study the effects of both fish and vegetable oil feeding in obese Zucker rats. The effects of fish oil feeding on several aspects of liver lipid metabolism were measured. These included mitochondrial respiration and $\beta$-oxidation, peroxisomal $\beta$-oxidation, and activities of malic enzyme $(E C 1.1 .1 .38,1.1 .1 .40)$, glucose-6-phosphate dehydrogenase (EC 1.1.1.49), glutathione peroxidase ( $E C 1.11,1.9)$, long-chain fatty acyl-CoA (LCFA$\mathrm{CoA})$ synthetase and hydrolase $(E C 3.1 .2 .2)$. Serum insulin, triiodothyronine $\left(\mathrm{T}_{3}\right)$, thyroxine $\left(\mathrm{T}_{4}\right)$, glucose, cholesterol, and triacylglycerol levels were also determined.

\section{MATERIALS AND METHODS}

\section{Reagents}

Coconut and safflower oils were purchased from United States Biochemical Corporation (Cleveland, $\mathrm{OH}$ ). Menhaden oil was obtained from Zapata Hayne Corporation (Reedville, VA). The menhaden oil had no added antioxidant. The naturally-present Vitamin E level was $50 \mathrm{ppm}$. [U- $\left.{ }^{14} \mathrm{C}\right]$ Palmitate (specific activity $53 \mu \mathrm{Ci} / \mathrm{mmol}$ ) was purchased from Dupont New England Nuclear Products (North Billerica, MA). All other chemicals were obtained from Sigma Chemical Company (St Louis, MO).

\section{Animals and diets}

Male, lean $(F a /$ ? ) and obese ( $f a / f a)$ Zucker rats ( 8 weeks old) from a colony maintained at the Hormel Institute Animal Facility were used. Rats were individually caged and kept at $21^{\circ}$ with a $12 \mathrm{~h}$ light $-12 \mathrm{~h}$ dark cycle. All rats were fed on ground laboratory chow for 2 weeks to adapt them to eating from food cups. At 10 weeks of age, feeding of the experimental diets was initiated. The rats were divided into six groups ( $n$ six to eight rats): lean coconut (LC), lean safflower (LS), lean menhaden (LM), obese coconut (OC), obese safflower (OS), and obese menhaden (OM). The initial body-weights ( $\mathrm{g}$ ) of each group were as follows: LC 234 (SD 23), LS 237 (SD 13), LM 239 (SD 12), OC 305 (SD 34), OS 307 (SD 31), OM 305 (SD 19), with obese rats weighing significantly more than lean rats. Exact numbers per measurement are shown in tables and figure legends.

The composition of the experimental diets is given in Table 1. All diets contained $20 \mathrm{~g}$ maize oil $/ \mathrm{kg}$ to ensure that essential fatty acids were provided in adequate amounts, especially in the coconut oil diet. Diets were prepared in small batches ( $3 \mathrm{~d}$ supply) in order to avoid autoxidation of the polyunsaturated fatty acids in the menhaden and safflower oils. Following preparation, the diets were flushed with nitrogen and stored at $-20^{\circ}$. Fresh diets were given to rats daily and leftover food was discarded.

\section{Dietary fatty acid analysis}

A portion $(1 \mathrm{~g})$ of each diet was extracted with $25 \mathrm{ml}$ chloroform-methanol $(1: 1, \mathrm{v} / \mathrm{v})$ mixture. The solids were removed by centrifugation and re-extracted. The extracts were pooled and evaporated to dryness on a rotary evaporator. The lipid was then dissolved in 
Table 1. Components of the different diets $(\mathrm{g} / \mathrm{kg})$

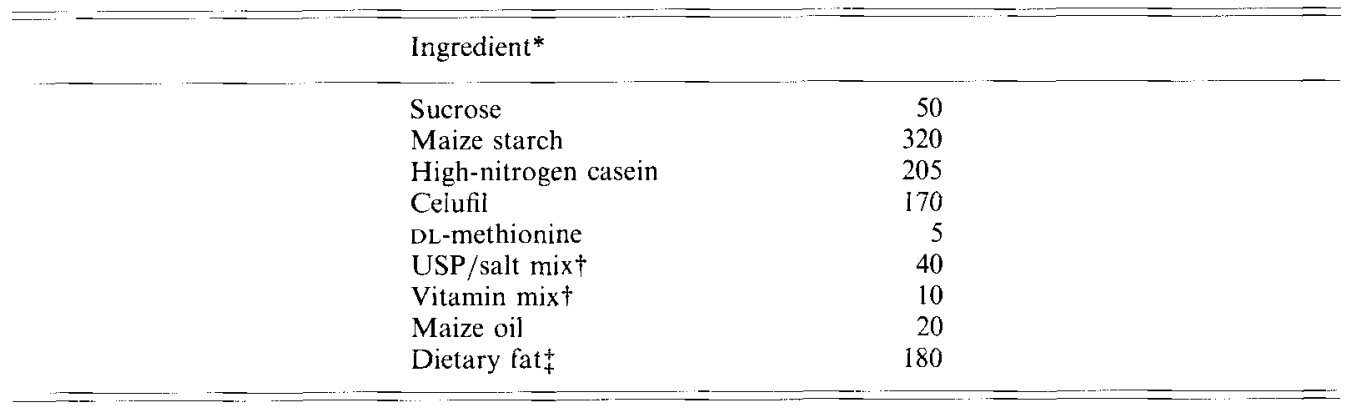

* All ingredients were purchased from United States Biochemical, Cleveland, Ohio, except for menhaden oil which was a gift from Zapata Hayne Corporation, Reedville, Virginia.

t The composition of salt and vitamin mixtures can be obtained from the United States Biochemical Corporation Catalog, Catalog nos. 21416 and 23431, respectively, and have previously been described in detail (Cleary, 1986).

$\ddagger$ Either coconut, safflower, or menhaden oil.

chloroform, filtered and evaporated to dryness with $\mathrm{N}_{2}$. The extracted lipid was dissolved in $2 \mathrm{ml}$ chloroform; $100 \mu \mathrm{l}$ of the lipid extract was esterified with $2 \mathrm{ml} 3 \mathrm{M}$-hydrochloric acid-methanol mixture at $90^{\circ}$ for $90 \mathrm{~min}$ in tightly capped tubes after flushing with $\mathrm{N}_{2}$. After cooling, $2 \mathrm{ml}$ water was added and the methyl esters were extracted with $5 \mathrm{ml}$ hexane, twice. The hexane extracts were pooled and evaporated to dryness with $\mathrm{N}_{2}$. The methyl esters were dissolved in $100 \mu \mathrm{l}$ dichloromethane. Fatty acids were analysed on a HewlettPackard 5840 A gas-liquid chromatograph equipped with a $30 \mathrm{~m}$ DB-225 capillary column. Results of the diet fatty acid composition are shown in Table 2. As anticipated, the majority of fatty acids in the coconut oil diet were saturated and of chain length sixteen or less. The safflower oil diet contained $75 \mathrm{~mol}$ linoleic acid/100 mol, and the menhaden oil diet was enriched in EPA and DHA. Coconut and menhaden oil had similar linoleic acid contents.

Daily food intake and weekly body-weights were recorded. At the end of 10 weeks, when the rats were 20 weeks old, they were killed by guillotine after an overnight fast $(12 \mathrm{~h})$. Blood was collected from the trunk and serum separated and stored at $-70^{\circ}$. Livers were removed and weighed.

\section{Serum measurements}

Cholesterol, triacylglycerol and glucose were determined using kits purchased from Sigma Chemical Company (St Louis, MO). Insulin, $\mathrm{T}_{3}$ and $\mathrm{T}_{4}$ were determined by radioimmunoassay kits purchased from Cambridge Medical Diagnostics (Billerica, MA).

\section{Mitochondrial respiration}

Mitochondria from liver were isolated and state 3 (respiration in the presence of ADP) and 4 (respiration in the absence of ADP) respiratory rates were determined using either glutamate-malate or succinate as substrates. These methods have been previously described in detail (Mohan \& Cleary, 1988). A Gilson oxygraph with a Clark-type electrode was used. The isolated mitochondria had ADP:oxygen ratio between 2.6 and 2.9 with glutamatemalate as substrate and with succinate the values were between 1.7 and 1.9 . The respiratory control ratio with glutamate-malate varied between 7 and 8 and with succinate it was between 5 and 6.5 . 
Table 2. Fatty acid composition of diets*

\begin{tabular}{|c|c|c|c|}
\hline $\begin{array}{l}\text { Fatty } \\
\text { acids }\end{array}$ & $\begin{array}{c}\text { Coconut } \\
\text { oil }\end{array}$ & $\begin{array}{c}\text { Safflower } \\
\text { oil }\end{array}$ & $\begin{array}{c}\text { Menhaden } \\
\text { oil }\end{array}$ \\
\hline $8: 0$ & $7 \cdot 4$ & - & - \\
\hline $10: 0$ & $5 \cdot 9$ & - & - \\
\hline $12: 0$ & $44 \cdot 0$ & - & - \\
\hline $14: 0$ & $16 \cdot 5$ & - & $8 \cdot 7$ \\
\hline $16: 0$ & $8 \cdot 6$ & $7 \cdot 3$ & $17 \cdot 1$ \\
\hline $16: 1 n-9$ and $n-7$ & - & - & $11 \cdot 0$ \\
\hline $18: 0$ & $2 \cdot 3$ & $2 \cdot 1$ & $2 \cdot 6$ \\
\hline $18: \ln -9$ & $7 \cdot 3$ & $11 \cdot 3$ & 100 \\
\hline $18: 1 n-7$ & - & - & $2 \cdot 6$ \\
\hline $18: 2 n-6$ & $6 \cdot 4$ & $75 \cdot 2$ & $6 \cdot 9$ \\
\hline $18: 3 n-3$ & - & - & $1 \cdot 0$ \\
\hline $20: \ln -9$ & - & - & $1 \cdot 1$ \\
\hline $20: 5 n-3$ & - & - & 11.9 \\
\hline $22: 5 n-3$ & - & $\ldots$ & $1 \cdot 7$ \\
\hline $22: 6 n-3$ & - & - & $6 \cdot 0$ \\
\hline Saturated fatty acids & $84 \cdot 7$ & $9 \cdot 4$ & $28 \cdot 4$ \\
\hline Monounsaturated fatty acids & $7 \cdot 3$ & $11 \cdot 3$ & $24 \cdot 7$ \\
\hline Polyunsaturated fatty acids & $6 \cdot 4$ & $75 \cdot 2$ & $27 \cdot 5$ \\
\hline$n-3$ fatty acids & - & - & $20 \cdot 6$ \\
\hline$n-6$ fatty acids & $6 \cdot 4$ & $75 \cdot 2$ & $6 \cdot 9$ \\
\hline$n-9$ fatty acids & $7 \cdot 3$ & $11 \cdot 3$ & 247 \\
\hline $\mathrm{P}: \mathrm{S}$ ratio & 0.08 & $8 \cdot 0$ & 0.97 \\
\hline
\end{tabular}

$P: S$, polyunsaturated : saturated fatty acids; - fatty acids less than $1 \mathrm{~mol} / 100 \mathrm{~mol}$ are not reported.

* Composition is reported relative to total fatty acids (mol/100 mol) of the extracted dietary lipid (see pp. 286-287). Each value is the average of two determinations.

\section{Mitochondrial $\beta$-oxidation}

A spectrophotometric method was used to determine fatty acid $\beta$-oxidation of isolated mitochondria (Osmundsen, 1981). Briefly, to a reaction mixture of 122 mm-potassium chloride, 9.4 mM-HEPES (pH 7.2), 0.09 mm-EDTA, 0.5 mm-potassium ferricyanide, $1.0 \mathrm{~mm}$ ADP, $1.0 \mathrm{~mm}$-potassium hydrogen phosphate, $1.0 \mathrm{~mm}$-potassium cyanide, $0.3 \mathrm{mg}$ cytochrome $\mathrm{C}$, and $4.5 \mathrm{mg}$ bovine serum albumin, $10 \mu \mathrm{l}$ of a mitochondrial suspension containing about $0.30-0.50 \mathrm{mg}$ protein was added, followed by $6 \mu \mathrm{g}$-rotenone, $20 \mu \mathrm{M}$ palmitoyl carnitine, and $10 \mathrm{~mm}$-oxalacetate $(\mathrm{pH} \mathrm{7.2)}$. The final volume was $3.0 \mathrm{ml}$ and the assay was carried out at room temperature. The change in absorbance at $420 \mathrm{~nm}$ due to reduction of ferricyanide was recorded. The rate of $\beta$-oxidation was expressed as nmoles ferricyanide reduced/mg protein per min.

\section{Peroxisomal $\beta$-oxidation}

Peroxisomal $\beta$-oxidation was measured by a spectrophotometric method (Lazarow, 1981) using a sample of the $600 \mathrm{~g}$ supernatant fraction obtained during mitochondrial isolation. The reaction was run at $37^{\circ}$ in a final volume of $1.0 \mathrm{ml}(\mathrm{pH} 80)$. The reaction mixture had the following composition: $47 \mathrm{~mm}$-Tris- $\mathrm{HCl}$ (pH 8.0), $0.2 \mathrm{~mm}-\mathrm{NAD}, 1 \mathrm{~mm}$-dithiothreitol, $75 \mu \mathrm{g}$ bovine serum albumin, Triton X-100 (0.1 g/l), 0.1 mm-CoA, 0.01 $\mu \mathrm{M}-\mathrm{FAD}, 1 \mathrm{~mm}-$ $\mathrm{KCN}, 0.1 \mathrm{mg}$ protein of $600 \mathrm{~g}$ supernatant fraction, and $0.01 \mathrm{~mm}$-palmitoyl-CoA. The change in absorbance due to NAD reduction was recorded and results expressed as nmol $\mathrm{NAD}$ reduced $/ \mathrm{mg}$ protein per $\mathrm{min}$. 
Table 3. Food intake, body-weight gain, and liver weights of lean $(L)$ and obese $(O)$ rats fed on coconut $(C)$, safflower $(S)$, or menhaden oil $(M)^{*}$

(Mean values and standard deviations for six rats/group)

\begin{tabular}{|c|c|c|c|c|c|c|c|c|c|c|c|c|}
\hline \multirow[b]{2}{*}{ Treatment group } & \multicolumn{2}{|c|}{$\mathbf{L C}$} & \multicolumn{2}{|c|}{ LS } & \multicolumn{2}{|c|}{ LM } & \multicolumn{2}{|c|}{$\mathrm{OC}$} & \multicolumn{2}{|c|}{ OS } & \multicolumn{2}{|c|}{$\mathrm{OM}$} \\
\hline & Mean & SD & Mean & SD & Mean & $\mathrm{SD}$ & Mean & SD & Mean & $\mathrm{SD}$ & Mean & SD \\
\hline $\begin{array}{l}\text { Total food intake } \\
\text { (g/10 weeks) }\end{array}$ & $1280^{\mathrm{a}}$ & 64 & $1199^{a}$ & 47 & $1182^{\mathrm{a}}$ & 52 & $1743^{\mathrm{b}}$ & 208 & $1532^{\mathrm{b}}$ & 118 & $1263^{a}$ & 171 \\
\hline Final body-wt (g) & $365^{a}$ & 19 & $367^{a}$ & 20 & $367^{a}$ & 24 & $549^{\circ}$ & 59 & $532^{\mathrm{c}}$ & 36 & $455^{\prime \prime}$ & 45 \\
\hline Total liver wt (g) & $8 \cdot 7^{\mathrm{a}}$ & $0 \cdot 6$ & $9 \cdot 3^{a}$ & $0 \cdot 5$ & $9 \cdot 8^{\mathrm{a}}$ & 0.6 & $15 \cdot 2^{\mathrm{b}}$ & $2 \cdot 6$ & $16 \cdot 3^{\mathrm{b}}$ & $2 \cdot 2$ & $15 \cdot 6^{\mathrm{b}}$ & $2 \cdot 8$ \\
\hline $\begin{array}{l}\text { Liver wt }(\mathrm{g} / \mathrm{kg} \\
\text { body-wt) }\end{array}$ & $24^{a}$ & 1 & $23^{a}$ & 1 & $27^{b}$ & 1 & $28^{b}$ & 4 & $31^{\circ}$ & 4 & $35^{\mathrm{a}}$ & 6 \\
\hline
\end{tabular}

$a, b, c, u$, Values with different superscript letters were significantly different from each other $(2 \times 3$ ANOVA and $F$ test, $P<0.05$ ).

* For details of treatments, see p. 286.

\section{Enzymes}

Glutathione peroxidase (Tappel, 1978), malic enzyme (Ochoa, 1955), and glucose6-phosphate dehydrogenase (Glock \& McLean, 1953) activities were measured in the liver cytosolic fraction ( $100000 \mathrm{~g}$ supernatant fraction). The cytosolic fraction was obtained as follows: liver was homogenized $(14 \mathrm{~g} / \mathrm{l})$ in $0.25 \mathrm{M}$-sucrose, $1 \mathrm{~mm}$-EDTA and centrifuged at $10000 \mathrm{~g}$ for $10 \mathrm{~min}$. The resultant supernatant fraction was centrifuged at $100000 \mathrm{~g}$ for $1 \mathrm{~h}$. The supernatant fraction was collected and used for enzyme assays. LCFA-CoA hydrolase and synthetase activities were assayed in liver mitochondria and microsomal fractions (Berge \& Farstad, 1981; Tanaka et al. 1981).

\section{Statistics}

Values are presented as means and standard deviations. The data were analysed by $2 \times 3$ ANOVA followed by an $F$ test to determine significance between specific groups (Winer, 1971). When only ANOVA for genotype was significant, results are described for lean $v$. obese groups. When results for diet groups were significant, groups are described as coconut, safflower or menhaden oil. When significant interactions between specific groups were present, individual group designations are used (LC, LM, etc.). A significance level of $P<0.05$ was used.

\section{RESULTS}

\section{Food intake and body and liver weights}

Cumulative food intake was similar among the three groups of lean rats (Table 3). OM rats had a value slightly higher than that of the lean rats. Food intake levels of the OC and OS groups were significantly higher than those of the other groups. Final body-weights were similar among the three groups of lean rats (Table 3). The OM group had lower bodyweights compared with the OC and OS groups which had similar weights. Obese rats had higher body-weights than lean rats.

Liver weights were similar for all lean rats and for all obese rats (Table 3). Obese rats had higher liver weights than lean rats. However, when liver weight was calculated on a bodyweight basis, menhaden oil rats had larger values compared with rats fed on the other two diets within each genotype (Table 3 ). OM rats had greater liver weight on a body-weight basis than did all other groups. 


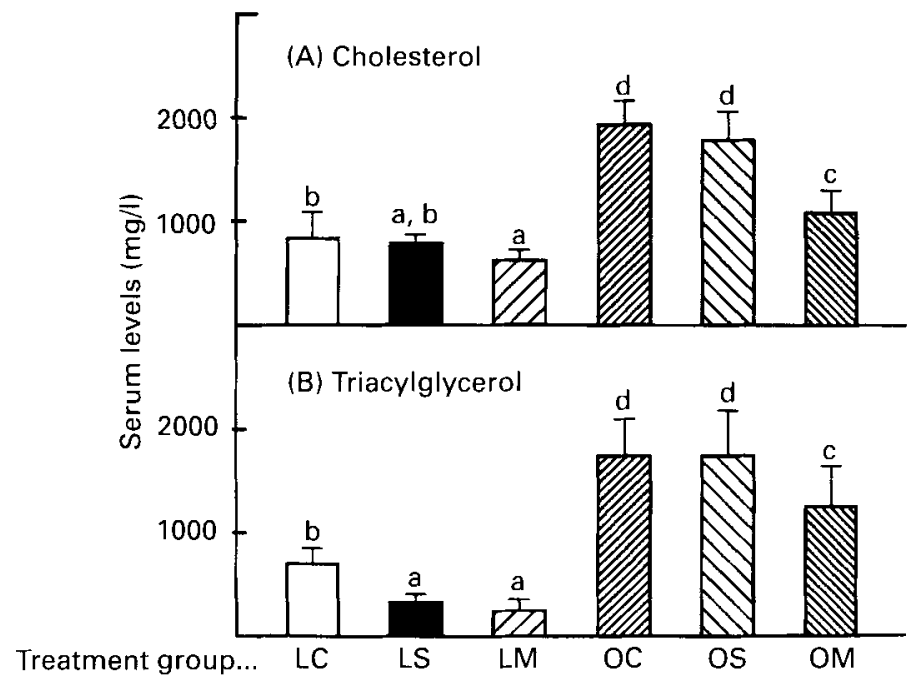

Fig. 1. Effect of feeding coconut (C), safflower (S), or menhaden oil (M) to lean (L) and obese (O) Zucker rats on serum cholesterol (A) and triacylglycerol (B) levels. For details of treatments, see p. 286. Values are means and standard deviations, represented by vertical bars, for six rats. ${ }^{\text {a }, ~ b . c, c}$, Means with different superscript letters were significantly different from each other by $2 \times 3$ ANOVA, $P<0 \cdot 05$.

\section{Serum measurements}

Serum cholesterol levels of the LM rats were significantly lower than those of the LC rats (Fig. 1(A)). The LS rats had serum cholesterol levels intermediate between LC and LM rats. The OM group had a significantly lower serum cholesterol level compared with both the OC and OS groups, but cholesterol values of all obese rats were higher than those of the lean rats. Serum triacylglycerol concentrations were lower in the LM and LS groups compared with the value obtained for the LC group (Fig. 1(B)). The OM group had significantly lower triacylglycerol levels compared with $O C$ and OS groups. In general, the obese rats had several-fold higher triacylglycerol values than did lean rats.

Serum glucose (Fig. 2(A)) and insulin levels (Fig. 2(B)) were similar in the three lean groups. In the obese groups, $O M$ and $O C$ rats had similar serum glucose and insulin values that were significantly lower than those of the OS rats. In fact, serum insulin values of OS rats were twice those of the two other obese groups. Obese rats had higher levels of glucose and insulin compared with those of the lean rats.

Serum $\mathrm{T}_{3}$ levels in LS, LM, and OM groups were similar and were lower than those of LC, OC, and OS rats (Fig. 2(C)) which also had similar $\mathrm{T}_{3}$ levels. The $\mathrm{T}_{4}$ levels of the $\mathrm{LS}$ group were the highest (Fig. 2(D)) and were followed by those of LC and LM rats. Serum $\mathrm{T}_{4}$ levels of $\mathrm{OC}$ and $\mathrm{OS}$ groups were similar and lower than those of all lean groups. OM rats had the lowest $T_{4}$ levels.

\section{Hepatic mitochondrial respiration}

State 3 (Fig. 3(A)) and state 4 (Fig. 3(B)) rates of mitochondrial respiration in the presence of glutamate-malate were lower in the menhaden oil rats compared with rates of rats fed on either coconut or safflower oil. The succinate-supported state 3 rate was significantly lower in menhaden oil rats compared with the rats fed on coconut or safflower oil (Fig. $4(\mathrm{~A})$ ). State 4 rates with succinate were similar in LC, LS, LM, and OM rats and were lower than those of OC and OS rats (Fig. 4(B)). 


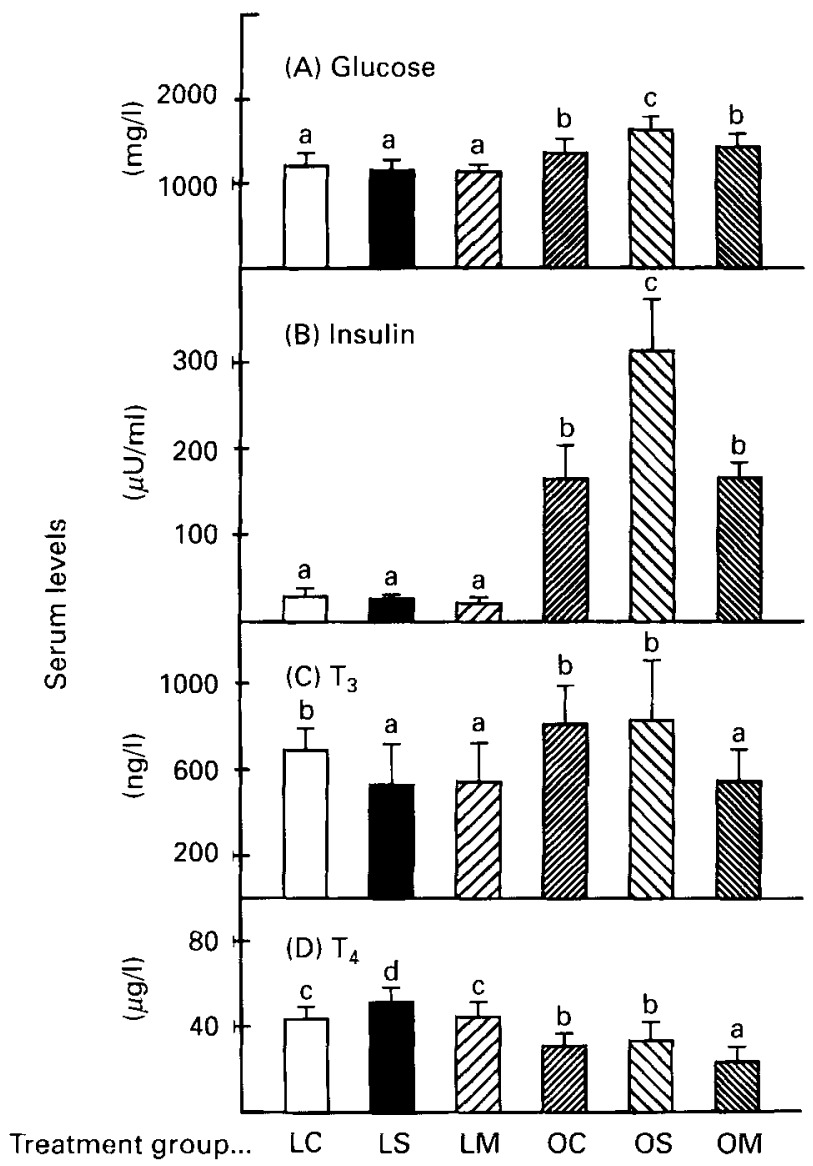

Fig. 2. Effect of feeding coconut (C), safflower (S), or menhaden oil (M) to lean (L) and obese (O) Zucker rats on serum glucose $(A)$, insulin $(B)$, triiodothyronine $\left(\mathrm{T}_{3} ; \mathrm{C}\right)$ and thyroxine $\left(\mathrm{T}_{4} ; \mathrm{D}\right)$ levels. For details of treatments, see p. 286. Values are means and standard deviations, represented by vertical bars, for six to eight rats. ${ }^{a}, \mathrm{~h}, \mathrm{c}, \mathrm{d}$, Means with different superscript letters were significantly different from each other by $2 \times 3$ ANOVA, $P<0.05$.

\section{Hepatic $\beta$-oxidation}

Mitochondrial fatty acid $\beta$-oxidation was not affected by dietary treatment. (Fig. 5(A)). However, obese rats had lower $\beta$-oxidation than did lean rats. Peroxisomal $\beta$-oxidation was significantly higher in menhaden oil rats compared with rats fed on either coconut or safflower oil (Fig. 5(B)). Peroxisomal $\beta$-oxidation was similar in coconut and safflower oil groups regardless of genotype.

\section{Liver enzymes}

In general, when considered within genotype, the activities of malic enzyme (Fig. 6(A)) and glucose-6-phosphate dehydrogenase (Fig. 6(B)) were lowest in menhaden oil rats and highest in safflower oil rats. Coconut oil rats had intermediate values. Obese rats tended to have higher activities of these two enzymes than did lean rats, except for OM rats whose values were similar to those of the lean rats.

The enzyme, glutathione peroxidase, is a scavenger for lipid hydroperoxides. This enzyme was measured as an indicator of lipid peroxidation that might be attributable to the diet composition. The activity of glutathione peroxidase did not demonstrate any 


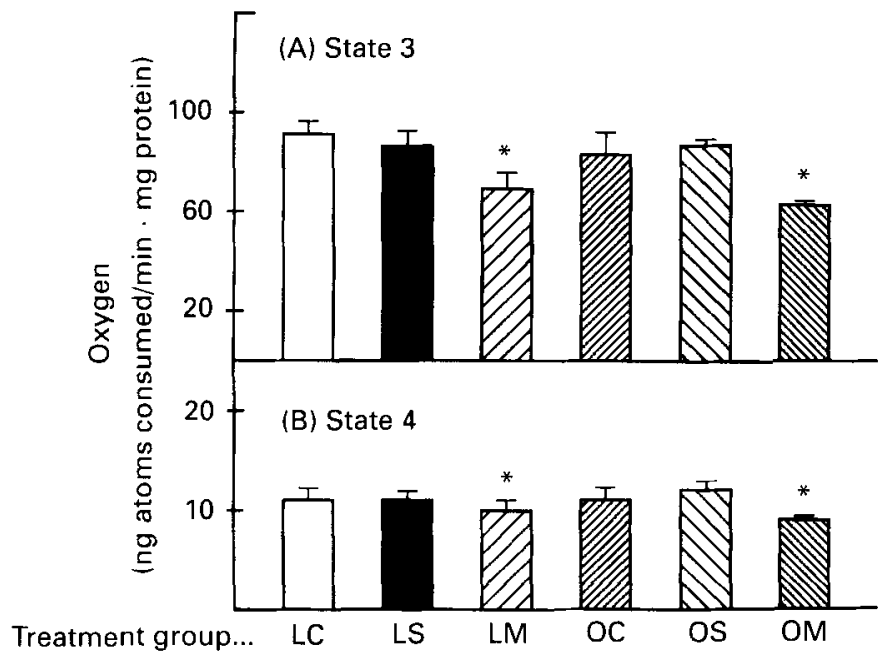

Fig. 3. Effect of feeding coconut (C), safflower (S), or menhaden oil (M) to lean (L) and obese (O) Zucker rats on liver mitochondrial respiration state 3 (A) and state 4 (B) rates in the presence of glutamate-malate. For details of treatments, see p. 286. Values are means and standard deviations, represented by vertical bars, for six to eight rats. * Significant differences between menhaden oil-fed rats and coconut and safflower oil-fed rats by $2 \times 3$ ANOVA, $P<0 \cdot 05$.

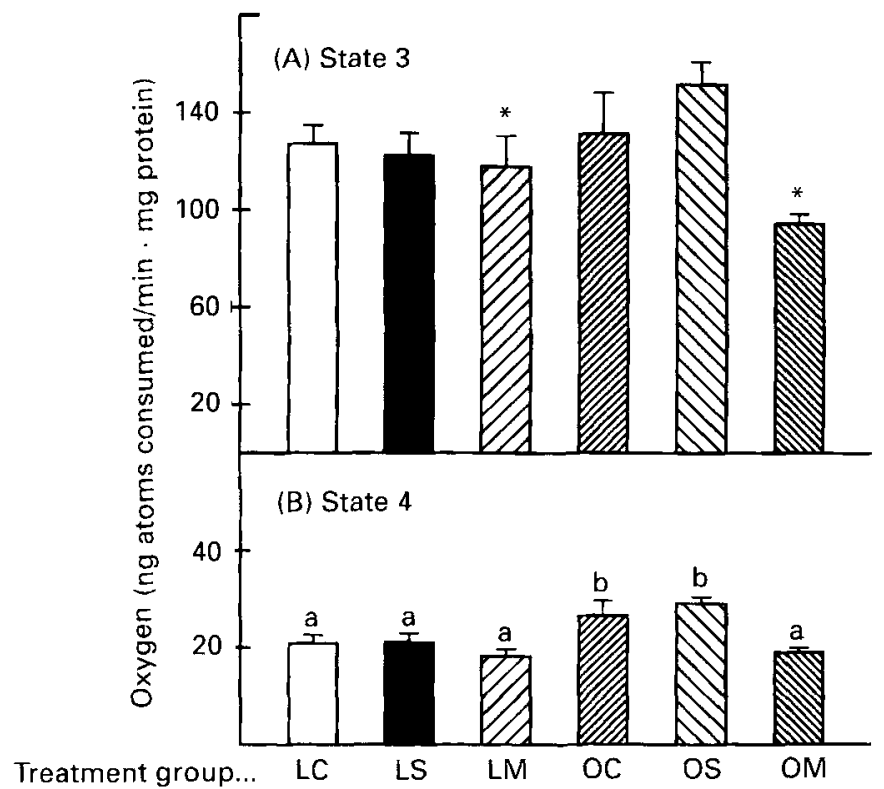

Fig. 4. Effect of feeding coconut (C), safflower (S), or menhaden oil (M) to lean (L) and obese (O) Zucker rats on liver mitochondrial state 3 (A) and state 4 (B) respiration rates in the presence of succinate. For details of treatments, see p. 286. Values are means and standard deviations, represented by vertical bars, for six to eight rats. ${ }^{a} \mathrm{~b}$, Means with different superscript letters were significantly different from each other by $2 \times 3$ ANOVA and $F$ test. * Significant differences between menhaden oil-fed rats and coconut and safflower oil-fed rats by $2 \times 3$ ANOVA, $P<0.05$. 


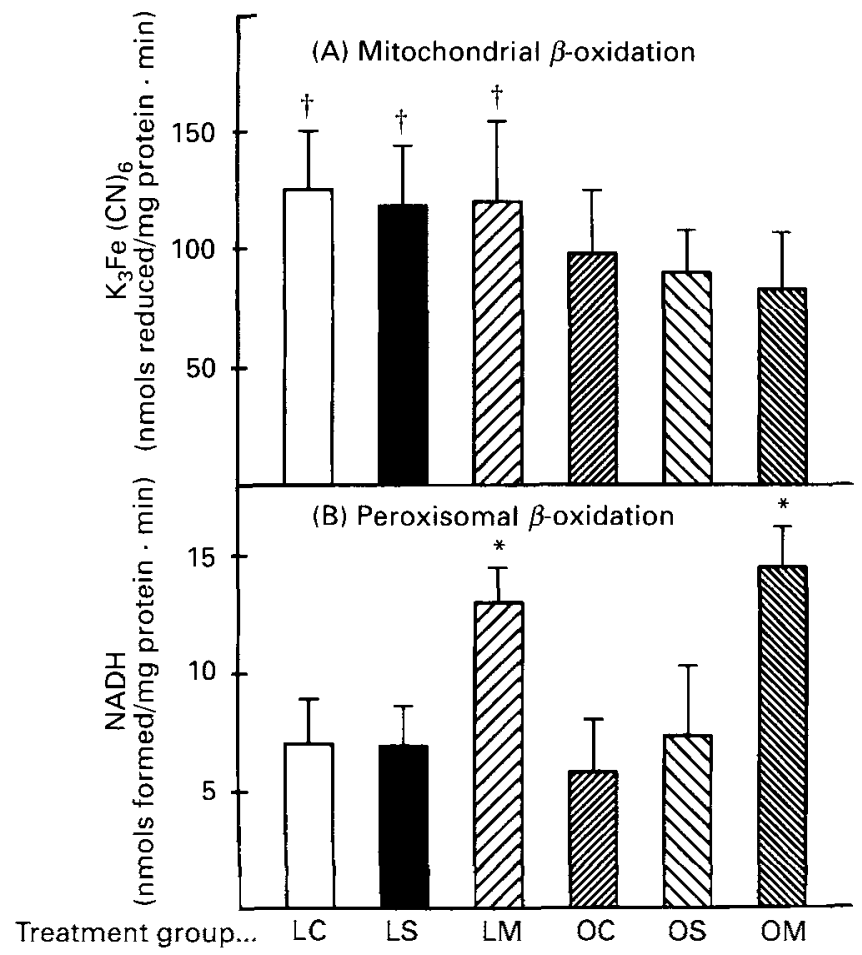

Fig. 5. Effect of feeding coconut (C), safflower (S), or menhaden oil (M) to lean (L) and obese (O) Zucker rats on mitochondrial $\beta$-oxidation (A) and peroxisomal $\beta$-oxidation (B). For details of treatments, see p. 286 . Values are means and standard deviations, represented by vertical bars, for six rats. ${ }^{*}$ Significant differences between menhaden oil-fed rats and coconut and safflower oil-fed rats by $2 \times 3$ ANOVA. $\uparrow$ Significant differences between lean and obese rats by $2 \times 3$ ANOVA, $P<0.05$.

consistent pattern with respect to either genotype or diet (Fig. 6(C)). The LC group had glutathione peroxidase activity intermediate between and not different from LM and LS rats, although LM and LS values were significantly different. The OC group had values similar to that of LC and LM groups and the OM and OS groups had the lowest activities.

LCFA-CoA hydrolase activity in the mitochondria of LM and OS rats was higher than that of all other groups (Table 4). The LS and OM rats had similar activity, but only LS rats had higher activity than LC rats. LC and OC rats had similar activity. The LCFA-CoA synthetase activity in the mitochondrial fraction was unaffected by dietary treatment or genotype.

In the microsomal fraction, LCFA-CoA hydrolase activity was highest in LM rats. The LC rats had the next highest, followed by that of LS rats. OM rats had higher activity than OS rats, but were similar to OC rats that had an intermediate value between that of OS and OM rats. Values for obese rats were less than those of lean rats. The LCFA-CoA synthetase activity in microsomes was not affected by dietary treatment or genotype.

\section{DISCUSSION}

Previous studies in rats have reported no effects of fish oil feeding on body-weight or food intake (Clarke et al. 1988; Dolphin et al. 1988; Herzberg \& Rogerson, 1988). In the present study, menhaden oil-fed lean rats grew in a similar fashion to their lean counterparts fed 


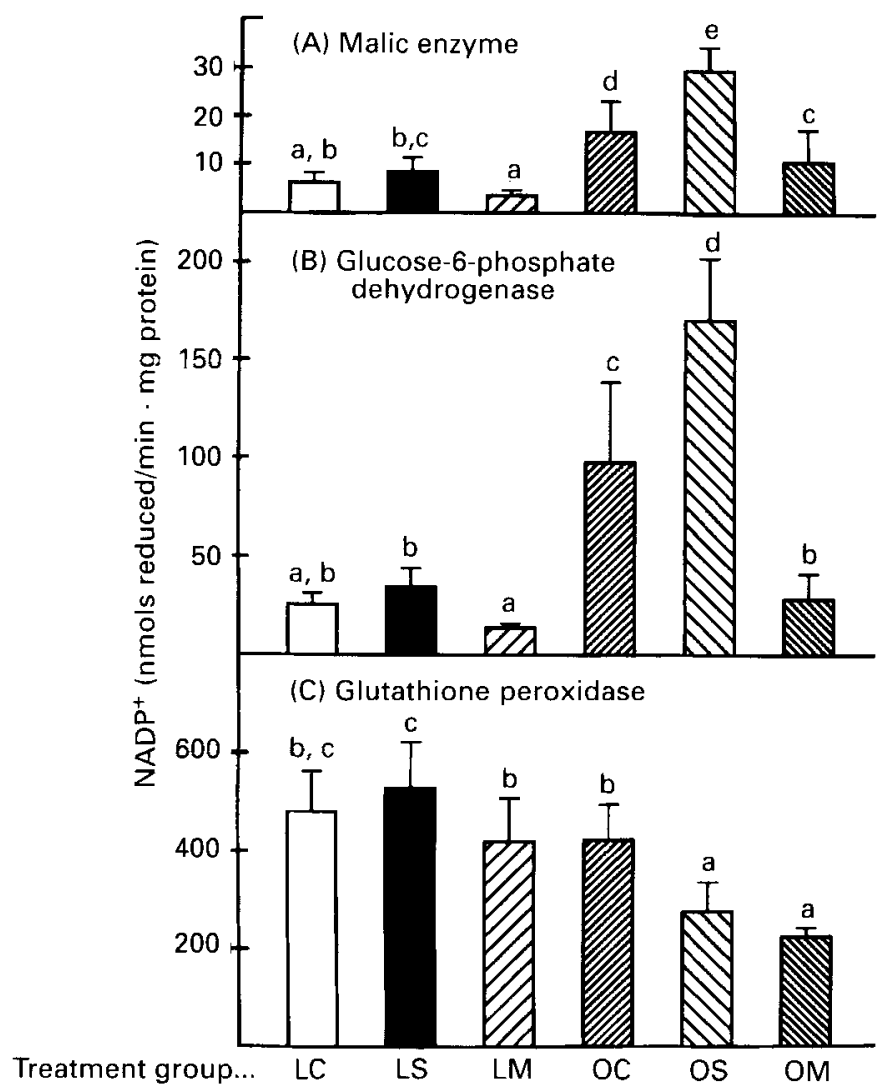

Fig. 6. Effect of feeding coconut (C), safflower (S), or menhaden oil (M) to lean (L) and obese (O) Zucker rats on hepatic malic enzyme $(E C 1.1 .1 .38, E C 1.1 .1 .40 ; \mathrm{A})$, glucose-6-phosphate dehydrogenase $(E C 1.1 .1 .49 ; \mathrm{B})$ and glutathione peroxidase ( $E C$ L $.11 .1 .9 ; C)$ activities. For details of treatment, see p. 286. Values are means and standard deviations, represented by vertical bars, for six to eight rats. a,t,c,d,e, Means with different superscript letters were significantly different from each other by $2 \times 3$ ANOVA, $P<0.05$.

on either coconut or safflower oil. Obese Zucker rats fed on menhaden oil, however, did not attain the body-weight of the obese rats fed on the other two oils. This appeared to be mediated by the lower food intake of the menhaden oil group. Similar findings for both body-weight and food intake were recently reported for female obese Zucker rats fed a diet containing MAXEPA (Jen et al. 1989). It is not readily apparent why obese Zucker rats respond in this manner, as corpulent rats did not respond to fish oil feeding with lowered body-weight (Dolphin et al. 1988). In fact, both male and female red fish oil-fed corpulent rats weighed significantly more than control corpulent rats. However, it is unlikely that the biochemical changes reported here are due to this slight lowering of food intake for several reasons. First, the lean menhaden oil rats whose food intake was not altered had metabolic changes that were similar to those of the menhaden oil obese rats. Second, other studies have shown that food restriction in obese Zucker rats does not alter their abnormalities of lipid metabolism (Martin \& Gahagan, 1977; Cleary et al. 1980; Cleary, 1986).

In the present study, both serum triacylglycerol and cholesterol were lower in obese male Zucker rats fed menhaden oil in comparison to both coconut and safflower oil rats. These results are somewhat different from those recently reported for female MAXEPA-treated Zucker rats where only triacylglycerol levels were lower (Jen et al. 1989). These differences 
Table 4. Long-chain fatty acyl CoA (LCFA-CoA) hydrolase (EC 3.1.2.2) and synthetase activities in lean $(L)$ and obese $(O)$ rats fed on coconut $(C)$, safflower $(S)$, or menhaden oil $(M)^{*}$

(Mean values and standard deviations for six rats/group)

\begin{tabular}{|c|c|c|c|c|c|c|c|c|c|c|c|c|}
\hline \multirow[b]{2}{*}{ Treatment group } & \multicolumn{2}{|c|}{$\mathrm{LC}$} & \multicolumn{2}{|c|}{ LS } & \multicolumn{2}{|c|}{$\mathbf{L M}$} & \multicolumn{2}{|c|}{$\mathrm{OC}$} & \multicolumn{2}{|c|}{ OS } & \multicolumn{2}{|c|}{$\mathrm{OM}$} \\
\hline & Mean & SD & Mean & SD & Mean & $\mathrm{SD}$ & Mean & SD & Mean & $\mathrm{SD}$ & Mean & SD \\
\hline \multicolumn{13}{|l|}{ Mitochondria } \\
\hline $\begin{array}{l}\text { LCFA-CoA } \\
\text { hydrolaset }\end{array}$ & $147^{\mathrm{a}, \mathrm{b}}$ & $3 \cdot 1$ & $18 \cdot 2^{\prime \prime}$ & $2 \cdot 5$ & $24 \cdot 2^{d}$ & 49 & $12 \cdot 1^{\mathrm{a}}$ & $2 \cdot 9$ & $21 \cdot 7^{4}$ & $6 \cdot 3$ & $16 \cdot 8^{\mathrm{b}, \mathrm{c}}$ & $5 \cdot 5$ \\
\hline $\begin{array}{r}\text { LCFA-CoA } \\
\text { synthetase }\end{array}$ & 46.9 & 16.6 & $41 \cdot 3$ & $8 \cdot 4$ & $50 \cdot 1$ & $12 \cdot 7$ & $41 \cdot 9$ & 17.4 & $38 \cdot 4$ & $7 \cdot 2$ & $42 \cdot 1$ & $5 \cdot 1$ \\
\hline \multicolumn{13}{|l|}{ Microsomes } \\
\hline $\begin{array}{c}\text { LCFA-CoA } \\
\text { hydrolase }\end{array}$ & $65.9^{4}$ & $13 \cdot 7$ & $55 \cdot 0^{\circ}$ & $7 \cdot 7$ & $78 \cdot 8^{e}$ & $17 \cdot 5$ & $30 \cdot 6^{a, b}$ & $11 \cdot 3$ & $25 \cdot 2^{\mathrm{a}}$ & $9 \cdot 3$ & $37 \cdot 1^{11}$ & $17 \cdot 4$ \\
\hline $\begin{array}{c}\text { LCFA-CoA } \\
\text { synthetase }\end{array}$ & $76 \cdot 0$ & $35 \cdot 4$ & $56 \cdot 7$ & $24 \cdot 7$ & $70 \cdot 5$ & 17.5 & $53 \cdot 8$ & $15 \cdot 4$ & $43 \cdot 6$ & $11 \cdot 0$ & $53 \cdot 0$ & $15 \cdot 6$ \\
\hline
\end{tabular}

an b., $\cdots, c$, Values with different superscript letters were significantly different from each other by $2 \times 3$ ANOVA and $F$ test, $P<0 \cdot 05$.

* For details of treatments, see p. 286.

$\dagger \mathrm{nmol}$ DTNB reduced/min per $\mathrm{mg}$ protein.

$\ddagger$ counts $/ \mathrm{min} \times 10^{6}$ per min per $\mathrm{mg}$ protein.

may be due to the previously described sex differences in cholesterol metabolism in this strain (Lin, 1985). In general, our findings are similar to those reported for human Types II b and V hyperlipidaemia subjects fed various types of fish oil diets or supplements (Harris et al. 1983; Phillipson et al. 1985; Herold \& Kinsella, 1986; Harris, 1989), where triacylglycerol and cholesterol levels are usually lowered by fish oil treatment. However, it is difficult to make direct comparisons between human and animal experiments, and results may be further affected by the hyperinsulinaemia and insulin resistance of the obese rats.

Due to these physiological characteristics, these rats have also been considered models of insulin-independent diabetes. Human trials of fish oil feeding in this type of diabetes have reported adverse effects on glycaemic control (Borkman et al. 1989; Glauber et al. 1988), although this is not always the case (Popp-Snijders et al. 1987). In the present study no differences were noted in the obese menhaden oil rats in comparison to coconut oil obese rats for either serum glucose or insulin values, suggesting no apparent adverse effects.

It is clear from the results of the present study that feeding these diets with oils of different fatty acid compositions (as shown in Table 2) causes alterations of many metabolic activities in livers of both lean and obese Zucker rats. A number of these findings could play a role in the lowering of serum lipids. For example, in both the lean and obese menhaden oil rats, the activities of hepatic malic enzyme and glucose-6-phosphate dehydrogenase were lowered in parallel with lower serum cholesterol and triacylglycerol levels. Other reports have also shown that fish oil feeding lowers activities of these enzymes in comparison with vegetable oils (Iritani et al. 1980; Johnson \& Berdanier, 1987; Jen et al. 1989). The lowered activities of these two enzymes would theoretically result in decreased production of NADPH which could then affect rates of either lipogenesis or cholesterolgenesis, or both. Lowered hepatic lipogenesis rates in perfused livers from fish oil-fed rats have been reported compared with rates obtained from livers of rats fed on either commercial rodent food or a diet with safflower oil (Wong et al. 1984). In addition, amounts of newly synthesized fatty acids in very-low-density lipoproteins were lower in the 
fish oil rats. It has also been reported that dietary fish oil feeding lowers fatty acid synthetase mRNA levels (Clarke \& Armstrong, 1988).

An interesting observation made in the present study was that activities of these two lipogenic enzymes were higher in livers of obese rats fed on safflower oil when compared with activities from livers of obese rats fed on the other two diets. This was an unexpected finding in comparison with coconut oil. It is possible that the high insulin levels present in the obese safflower group could affect the activities of these enzymes. Insulin administration has been shown to elevate these enzymes several-fold (Goodridge \& Adelman, 1976; Nepokroeff et al. 1976; Winberry et al. 1980) and in insulin deficiency, as in insulindependent diabetes, the enzyme activities were shown to be lowered (Nepokroeff et al. 1976).

The rats fed on menhaden oil in the present study had lowered rates of hepatic mitochondrial respiration. The lowered serum $T_{3}$ and $T_{4}$ levels may contribute to the suppression of mitochondrial respiration, as it is known that these hormones can alter mitochondrial function (Hoch, 1988). Earlier, Yamaoka et al. (1988) reported lowered heart mitochondrial respiration from Sprague-Dawley rats fed on sardine oil in comparison with mitochondria from rats fed on maize oil. This effect was attributed to measured changes in the mitochondrial phospholipid fatty acid composition. The physiological significance of the lower mitochondrial respiration and its effect on cellular metabolism is not clear. Lower energy potential of the cell should be reflected by the metabolic rate of the rat, but information on this in relation to fish oil feeding has not been determined. On the other hand, the effects of lower mitochondrial respiration would be negated by the higher liver mass in relation to body-weight observed in menhaden oil rats.

The elevated peroxisomal $\beta$-oxidation in the livers of menhaden oil rats in the present study confirm previous observations (Yamazaki et al. 1987). Osmundsen \& Jornstad (1985) have suggested that this is a compensatory response following inhibition of mitochondrial $\beta$-oxidation by $n-3$ fatty acids. In the present study, there was no effect on mitochondrial $\beta$-oxidation. This can be explained by the elevated activity of LCFA-CoA hydrolase and unaltered activity of LCFA-CoA synthetase in mitochondria and microsomes. This pattern of enzyme activity would maintain the concentration of LCFA-CoA below the inhibitory level in mitochondria. This may be an important mechanism to regulate the levels of acyl$\mathrm{CoA}$. Since peroxisomes have the capacity readily to oxidize long- and very-long-chain fatty acids to medium-chain acyl esters, they may be directly activated in response to the high concentration of these substrates provided by the fish oil diet. Berge et al. (1988) have recently suggested that the message for induction of peroxisomal $\beta$-oxidation is the presence of elevated cellular levels of LCFA-COA. Several investigators have suggested that hypolipidaemic drugs and fish oil (Yamazaki et al. 1987; Flatmark et al. 1988) may act through similar mechanisms to lower serum lipids, i.e., peroxisomal $\beta$-oxidation.

The initial mechanism by which fish oil consumption results in these many metabolic changes is at present not clear. It is well known that cellular and subcellular membrane composition, particularly that of phospholipids, is altered in response to changes in dietary fat. Further, in vitro and in vivo modifications of membrane composition have been shown to modulate membrane functions including transport, receptors, and enzyme activities (Kaduce et al. 1977; Sanderman, 1978; Roman et al. 1979; Pilch et al. 1980; McCaleb \& Donner, 1981). Thus, modification of membrane composition due to fish oil feeding may be the primary factor leading to sequelae of biochemical events. For example, Strum-Odin et al. (1987) have hypothesized that enrichment of phospholipid composition with specific fatty acids could influence activities of enzymes associated with the triacylglycerol pathway. Using cultured hepatocytes, they have shown that enrichment of membranes with EPA led to lowered triacylglycerol synthesis and secretion. This was attributed to an altered 
partitioning of palmitic acid away from triacylglycerol synthesis and towards fatty acid oxidation due to lowered diacylglycerol transferase (EC 2.3.1.20) activity inhibition. Some of the metabolic perturbations induced by fish oil feeding could also be due either to enhanced oxygen free radical generation (Gower, 1988) which would lead to formation of lipid hydroperoxides, or to the presence of other oxidation products of polyunsaturated fatty acids (Vanrollins et al. 1988), or both. The lack of elevated activity of glutathione peroxidase would suggest that this does not occur. Recently, Flatmark et al. (1988) have shown that feeding partially-hydrogenated fish oil to rats elicited a rapid 12 -fold rise in cellular mRNA levels specific for a bifunctional enzyme, enoyl-CoA hydratase $(E C$ $4.2 .1 .17): \beta$-hydroxyacyl-CoA dehydrogenase $(E C 1.1 .1 .35)$ of peroxisomal $\beta$-oxidation. This suggests another possible mode, where modulation of gene expression by $n-3$ fatty acids or their metabolites can occur. However, a direct interaction of $n-3$ fatty acids, etc. with the nuclear genome has to be shown before this can be accepted.

The authors are indebted to Mr Mickey Radigan and the Zapata Hayne Corporation for the menhaden oil. This research was supported by NIH Grants HL08214 and HD25306 and by the Hormel Foundation.

\section{REFERENCES}

Berge, R. K. \& Farstad, M. (1981). Long-chain fatty acyl-CoA hydrolase from rat liver mitochondria. Methods in Enzymology 71, 234-242.

Berge, R. K., Nilsson, A. \& Husoy, A. M. (1988). Rapid stimulation of liver palmitoyl-CoA synthetase, carnitine palmitoyl transferase and glycerophosphate acyltransferase compared to peroxisomal $\beta$-oxidation and palmitoyl-CoA hydrolase in rats fed high-fat diets. Biochimica et Biophysica Acta 960, 417-426.

Borkman, M., Chisholm, D. J., Furler, S. M., Storlien, L. H., Kraegen, E. W., Simons, L. A. \& Chesterman, C. N. (1989). Effect of fish oil supplementation on glucose and lipid metabolism in NIDDM. Diabetes 38, 1314-1319.

Clarke, S. D. \& Armstrong, M. K. (1988). Suppression of rat liver fatty acid synthetase m-RNA level by dietary fish oil. Federation of the American Society for Experimental Biology Journal 2, 852a.

Clarke, S. D., Benjamin, L., Bell, L. \& Phinney, S. D. (1988). Fetal growth and fetal lung phospholipid content in rats fed safflower oil, menhaden oil or hydrogenated coconut oil. American Journal of Clinical Nutrition 47 , $828-835$

Cleary, M. P. (1986), Consequences of restricted feeding/refeeding cycles in lean and obese female Zucker rats. Journal of Nutrition 116, 290-303.

Cleary, M. P., Vasselli, J. R. \& Greenwood, M. R. C. (1980). Development of obesity in Zucker obese (fa/fa) rat in absence of hyperphagia. American Journal of Physiology 238, E284-E292.

Clubb, F. J., Schmitz, J. M., Butler, M. M., Buja, L. M., Willerson, J. T. \& Campbell, W. B. (1989). Effect of dietary omega-3 fatty acid on serum lipids, platelet function, and atherosclerosis in Watanabe heritable hyperlipidaemic rabbits. Arteriosclerosis 9, 529--537.

Dolphin, P. J., Amy, R. M., Koeslag, D. G., Limoges, B. F. \& Russell, J. C. (1988). Reduction of hyperlipidaemia in the LA/N-corpulent rat by dietary fish oil containing $n-3$ fatty acids. Biochimica et Biophysica Acta $\mathbf{9 6 2}$, 317-329.

Flatmark, T., Astrid, N., Jon, K., Thors, E. S., Miriam, H. F., Harald, K. \& Erling, E. N. (1988). On the mechanism of induction of the enzyme systems for peroxisomal $\beta$-oxidation of fatty acids in rat liver by diets rich in partially hydrogenated fish oil. Biochimica et Biophysica Acta 962, 122-130.

Glauber, H., Wallace, P., Griver, K.\& Brechtel, G. (1988). Adverse metabolic effect of omega-3 fatty acids in noninsulin dependent diabetes mellitus. Annals of Internal Medicine 108, 663-668.

Glock, G. \& McLean, P. (1953). Further studies on the properties and assay of glucose-6-phosphate dehydrogenase and 6-phosphogluconate dehydrogenase of rat liver. Biochemical Journal 55, 400-408.

Goodridge, A. G. \& Adelman, T. G. (1976). Regulation of malic enzyme synthesis by insulin, triiodothyronine and glucagon in liver cells in culture. Journal of Biological Chemistry 251, 3027-3032.

Gower, J. D. (1988). A role for dietary lipids and antioxidants in the activation of carcinogens. Free Radical Biology and Medicine 5, 95-111.

Harris, W. S. (1989). Fish oils and plasma lipid and lipoprotein metabolism in humans: a critical review. Journal of Lipid Research 30, 785-807.

Harris, W. S., Connor, W. E. \& McMurry, M. P. (1983). The comparative reductions of the plasma lipids and lipoproteins by dietary polyunsaturated fats: salmon oil versus vegetable oil. Metabolism 32, 179-184. 
Herold, P. M. \& Kinsella, J. E. (1986). Fish oil consumption and decreased risk of cardiovascular disease: a comparison of findings from animal and human feeding trials. American Journal of Clinical Nutrition 43, 566-598.

Herzberg, G. R. \& Rogerson, M. (1988). Hepatic fatty acid synthesis and triglyceride secretion in rats fed fructoseor glucose-based diets containing corn oil, tallow or marine oil. Journal of Nutrition 118, 1061-1067.

Hoch, F. L. (1988). Lipids and thyroid hormones. Progress in Lipid Research 27, 199-270.

Iritani, N., Inoguchi, K., Endo, M., Fukuda, E. \& Morita, M. (1980). Identification of shell fish fatty acids and their effects on lipogenic enzymes. Biochimica et Biophysica Acta 618, 378-382.

Jen, K-L. C., Alexander, M., Zhong, S., Rose, K., Lin, P. K. H. \& Kasim, S. E. (1989). Lipid lowering effect of omega-3 fatty acids in genetically obese Zucker rats. Nutrition Research 9, 1217-1228.

Johnson, B. J. \& Berdanier, C. D. (1987). Effect of menhaden oil on the responses of rats to starvation-refeeding. Nutrition Reports International 36, 809817.

Kaduce, T. L., Awad, A. B., Fontenelle, L. J. \& Spector, A. A. (1977). Effect of fatty acid saturation on $\alpha-$ aminoisobutyric acid transport in Ehrlich ascites cells. Journal of Biological Chemistry 252, 6624-6630.

Kinsella, J. E. (1987). Seafoods and Fish Oils in Human Health and Diseases. New York, NY: Marcel Dekker Inc.

Lazarow, P. B. (1981). Assay of peroxisomal $\beta$-oxidation of fatty acids. Methods in Enzymology 72, 315-319.

Leaf, A. \& Weber, P. C. (1988). Cardiovascular effects of $n-3$ fatty acids. New England Journal of Medicine 318 , $549-557$.

Lin, R. L. (1985). Serum cholesterol, lecithin-cholesterol acyltransferase, and hepatic hydroxy methylglutaryl Coenzyme A reductase activities of lean and obese Zucker rats. Metabolism 34, 19-24.

Martin, R. J. \& Gahagan, J. (1977). Serum hormone levels and tissue metabolism in pair-fed lean and obese Zucker rats. Hormone and Metabolic Research 9, 181-186.

McCaleb, M. L. \& Donner, D. B. (1981). Affinity of hepatic insulin receptor is influenced by membrane phospholipids. Journal of Biological Chemistry 256, $11051-11057$.

Mohan, P. F. \& Cleary, M. P. (1988). Effect of short-term DHEA administration on liver metabolism of lean and obese rats. American Journal of Physiology 255. El-E8.

Nepokroeff, C. M., Lakshmahan, M. R., Ness, G. C., Moseing, R. A., Kleinsek, D. A. \& Porter, I. W. (1976). Coordinate control of rat liver lipogenic enzymes by insulin. Archives of Biochemistry and Biophysics 162 , $340-344$.

Ochoa, S. (1955). Malic enzyme. Methods in Enzymology 1, 739-741.

Osmundsen, H. (1981). Spectrophotometric procedure for measuring mitochondrial $\beta$-oxidation. Methods in Enzymology 72, 306-314.

Osmundsen, H. \& Jornstad, K. B. (1985). Inhibitory effects of some long-chain unsaturated fatty acids on mitochondrial $\beta$-oxidation. Biochemical Journal 230, 329-337.

Phillipson, B. E., Rothrock, D. W., Connor, W. E., Harris, W. S. \& Illingworth, D. R. (1985). Reduction of plasma lipids, lipoproteins and apoproteins by dietary fish oil in patients with hypertriglyceridemia. New' England Journal of Medicine 312, 1210-1216.

Pilch, P. F., Thompson, P. A. \& Czech, M. P. (1980). Coordinate modulation of D-glucose transport activity and bilayer fluidity in plasma membrane derived from control and insulin-treated adipocytes. Proceedings of the National Academy of Sciences, U.S.A. 77, 915-918.

Popp-Snijders, S. C., Schouten, J. A., Heine, R. J., van der Meer, J. \& van der Veen, E. A. (1987). Dietary supplementation of omega-3 polyunsaturated fatty acids improves insulin sensitivity in non-insulin-dependent diabetes. Diabetes Research 4, 141-147.

Rich, S., Miller, J. F. Jr, Charous, S., Davis, H. R., Shanks, P., Glasov, S. \& Lands, W. E. (1989). Development of atherosclerosis in genetically hyperlipidaemic rabbits during chronic fish oil ingestion. Arteriosclerosis 9 , 189-194.

Roman, I., Maj, P. G., Nowicka, C. \& Angielski, S. (1979). Regulation of $\mathrm{Ca}^{2+}$ efflux from kidney and liver mitochondria by unsaturated fatty acids and $\mathrm{Na}^{+}$ion. European Journal of Biochemistry 102, 615-623.

Sanderman, H. Jr (1978). Regulation of membrane enzymes by lipids. Biochimica et Biophysica Acra 515, $209-237$.

Strum-Odin, R, Adkins-Finke, B., Blake, W. L., Phinney, S. D. \& Clarke, S. D. (1987). Modification of fatty acid composition of membrane phospholipid in hepatocyte monolayer with $n-3, n-6$ and $n-9$ fatty acids and its relationship to triacylglycerol production. Biochimica et Biophysica Acta 921, 378-391.

Tanaka, T., Hosaka, K. \& Numa, S. (1981). Long chain acyl-CoA synthetase from rat liver. Methods in Enzymology 71, 334-341.

Tappel, A. L. (1978). Glutathione peroxidase and hydroperoxides. Methods in Enzymology 52, $506-513$.

Vanrolins, M., Frade, P. D. \& Carretero, O. A. (1988). Oxidation of 5,8,11,14,17-eicosapentaenoic acid by hepatic and renal microsomes. Biochimica et Biophysica Acta 966, 133-149.

Winberry, L., Nakayama, R., Wolfe, R. \& Holten, D. (1980). Regulation of glucose-6-phosphate dehydrogenase activity in primary rat hepatocyte cultures. Biochemical and Biophysical Research Communications 96, 748-755.

Winer, B. J. (1971). Factorial experiments in which some of the interactions are confounded. Statistical Principles in Experimental Design, chapt 8, pp. 606-676. New York: McGraw-Hill.

Wong, S. H., Nestel, P. J., Trimble, R. P., Storer, G. B., Illman, R. J. \& Topping, D. L. (1984). The adaptive effects of dietary fish and safflower oil on lipid and lipoprotein metabolism in perfused rat liver. Biochimica et Biophysica Acta 792, 103-109. 
Yamaoka, S., Urade, R. \& Kito, M. (1988). Mitochondrial function in rats is affected by modification of membranc phospholipids with dietary sardine oil. Journal of Nutrition 118, 290-296.

Yamazaki, R. K., Shen, T. \& Schade, G. B. (1987). A diet rich in $(n-3)$ fatty acids increases peroxisomal $\beta$ oxidation activity and lowers plasma triacylglycerols without inhibiting glutathione-dependent detoxication activities in the rat liver. Biochimica et Biophysica Acta 920, 62-67.

Zucker, L. M. (1965). Hereditary obesity in the rat associated with hyperlipidaemia. Annals of the New York Academy of Sciences 131, 447-458.

Zucker, T.F. \& Zucker, L. M. (1962). Hereditary obesity in the rats associated with high serum fat and cholesterol. Proceedings of the Society for Experimental Biology and Medicine 110, 165-171. 